\title{
Anti-invasive and antiangiogenic effects of MMI-166 on malignant glioma cells
}

\author{
Hiromichi Nakabayashi*, Toshio Yawata and Keiji Shimizu
}

\begin{abstract}
Background: The constitutive overexpression of matrix metalloproteinases (MMPs) is frequently observed in malignant tumours. In particular, MMP-2 and MMP-9 have been reported to be closely associated with invasion and angiogenesis in malignant gliomas. Our study aimed to evaluate the antitumour effects of MMI-166 (Nalpha-[4-(2Phenyl-2H-tetrazole-5-yl) phenyl sulfonyl]-D-tryptophan), a third generation MMP inhibitor, on three human glioma cell lines (T98G, U87MG, and ONS12) in vitro and in vivo.

Methods: The effects of MMI-166 on the gelatinolytic activity was analysed by gelatine zymography. The anti-invasive effect of MMI-166 was analysed by an in vitro invasion assay. An in vitro angiogenesis assay was also performed. In vitro growth inhibition of glioma cells by MMI-166 was determined by the MTT assay. The effect of MMI-166 on an orthotropic implantation model using athymic mice was also evaluated.

Results: Gelatine zymography revealed that MMP-2 and MMP-9 activities were suppressed by MMI-166. The invasion of glioma cells was suppressed by MMI-166. The angiogenesis assay showed that MMI-166 had a suppressive effect on glioma cell-induced angiogenesis. However, MMI-166 did not suppress glioma cell proliferation in the MTT assay. In vivo, MMI-166 suppressed tumour growth in athymic mice implanted orthotropically with T98G cells and showed an inhibitory effect on tumour-induced angiogenesis and tumour growth. This is the first report of the effect of a third generation MMP inhibitor on malignant glioma cells.
\end{abstract}

Conclusions: These results suggest that MMI-166 may have potentially suppressive effects on the invasion and angiogenesis of malignant gliomas.

\section{Background}

Malignant gliomas are characterized by high invasive potential and strong angiogenic ability. The control of tumour invasion and angiogenesis are the key problems for the improvement of treatment results of malignant gliomas. Tumour invasion and angiogenic processes are involved in the degradation of the extracellular matrix (ECM) that surrounds tumour cells. Matrix metalloproteinases (MMPs) that degrade various ECM components are frequently expressed in malignant tumours, including gliomas, at higher levels than their benign counterparts $[1,2]$. MMPs are theoretically promising targets for new drugs to treat cancers. Several MMP inhibitors have been developed, and their clinical trials have begun in cancer patients [3-5]. Nevertheless, many clinical failures have

*Correspondence: blue_flare17@yahoo.co.jp

1 Department of Neurosurgery, Kochi Medical School Kochi University, Nankoku, Japan

Full list of author information is available at the end of the article made drug developers prudent, and the era of synthetic MMP inhibitors was thought to be finished. However, these failures of MMP inhibitor clinical trials in cancer were partly due to the inadvertent inhibition of MMP antitargets that are crucial for host protection. Achieving the selectivity of MMP inhibitor may validate clinical application of MMP inhibitors. It might be meaningful to test novel selective MMP inhibitors. Then, we aimed to examine the inhibitory effects of MMI-166 $\left(\mathrm{N}^{\alpha}-[4-(2-\right.$ Phenyl-2H-tetrazole-5-yl) phenyl sulfonyl]-D-tryptophan; $\mathrm{C}_{24} \mathrm{H}_{20} \mathrm{~N}_{6} \mathrm{O}_{4} \mathrm{~S}$ ) (Figure 1), a third generation MMP inhibitor, on the invasive and angiogenic processes of human malignant glioma cell lines in vitro and in vivo. MMI-166 has a selective spectrum of MMP inhibition (MMP-2, MMP-9, and MMP-14) in order to reduce side effects. The molecular weight of this inhibitor is 488.5 $\mathrm{Da}$, and it is expected to cross the blood-brain barrier. 


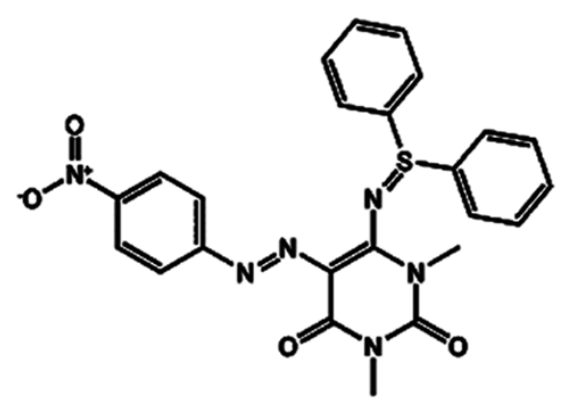

MMI-166 ( ${ }^{\alpha}$-[4-(2- Phenyl-2H-tetrazole-5-yl) phenyl sulfonyl]D-tryptophan; $\mathrm{C}_{24} \mathrm{H}_{20} \mathrm{~N}_{6} \mathrm{O}_{4} \mathrm{~S}$ )

Figure 1 The chemical structure of MMI-166. MMI-166, a third generation MMP inhibitor, selectively inhibits the activity of MMP-2, -9, and -14 .

This is the first report of the effect of a third generation MMP inhibitor on human malignant glioma cells.

\section{Methods}

\section{Glioma cell lines and cell culture}

Two human glioma cell lines (T98G and U87MG) were obtained from the American Type Culture Collection (Rockville, MD, USA). The ONS12 cell line was established from the resected tumour tissue of a 48-year-old female with glioblastoma in our hospital. These cell lines were maintained in Dulbecco's modified Eagle's medium (DMEM; Nikken Biomedical Laboratory, Kyoto, Japan) supplemented with $10 \%$ fetal bovine serum (FBS; Gibco BRL, Gaithersburg, MD, USA), penicillin (100 unit $/ \mathrm{mL})$, and streptomycin $(100 \mathrm{mg} / \mathrm{mL})$ at $37^{\circ} \mathrm{C}$ in tissue culture dishes (Asahi Techno Glass Corporation, Chiba, Japan) in a humidified incubator gassed with $5 \% \mathrm{CO}_{2}$.

\section{MMI-166}

MMI-166 was kindly provided by Shionogi Research Laboratory (Osaka, Japan). MMI-166 selectively inhibits the activity of MMP-2, -9, and -14 (IC50s: 0.4, 90, and 100 $\mathrm{nmol} / \mathrm{L}$, respectively) but not the activity of MMP-1, -3 , or -7 (IC50s: >1,000 nmol/L) [6].

\section{Gelatine zymography}

Gelatine substrate gel electrophoresis was performed to measure the levels of metalloproteinase activity in culture supernatants from the cell lines by using the gelatine zymography kit (Yagai Corporation, Tokyo, Japan). Glioma cell lines were seeded onto plates containing DMEM with $10 \%$ FBS. When the cells had grown to approximately $80 \%$ confluency, the medium was removed, and the cells were washed 3 times with DMEM to remove residual FBS. The cells were then cultured for $24 \mathrm{~h}$ in DMEM with $0.1 \%$ bovine serum albumin (BSA). After $24 \mathrm{~h}$, the culture medium was collected and centri- fuged twice at $800 \mathrm{rpm}$ for $5 \mathrm{~min}$. The supernatant $(20$ $\mu \mathrm{L}$ ) was electrophoresed on the gel supplied with the gelatine zymography kit. The gel was washed with two types of washing buffer for $30 \mathrm{~min}$ each and then incubated for $30 \mathrm{~h}$ at $37^{\circ} \mathrm{C}$ in the reaction buffer. To assess the MMP inhibitory activity of MMI-166, the gels were incubated in a reaction buffer containing various concentration levels of MMI-166 $(0,0.1,1,10$, and $100 \mu \mathrm{M})$. The gels were stained with Coomassie blue and then destained. The gelatinolytic activity was visualized as clear white bands against a blue background.

\section{Invasion assay}

The invasion assay was performed using Transwell invasion chambers (BioCoat; BD Biosciences, San Jose, CA, USA). Glioma cell lines were cultured in 24-well plates. An insert was used to divide each well of the plate into lower and upper chambers. The bottom of the insert was an $8.0-\mu \mathrm{m}$ pore size PET membrane coated with Matrigel (BD Biosciences). The lower chamber was filled with 700 $\mu \mathrm{L}$ DMEM supplemented with $0.1 \%$ BSA culture medium and human fibronectin $(12.5 \mu \mathrm{g} / \mathrm{dL}$, as a chemoattachment). The subconfluent cells were harvested and suspended in $500 \mu \mathrm{L}$ DMEM supplemented with $0.1 \%$ BSA culture medium containing one of various MMI-166 concentrations $(0.1-100 \mu \mathrm{M})$. The cells were subsequently cultured at a density of $5.0 \times 10^{4}$ cells/well in the upper chamber. After incubation for $23 \mathrm{~h}$, the cells present on the upper surface of the filters were removed with cotton swabs. The filters were fixed in $70 \%$ ethanol and stained with Giemsa. Cells on the lower surface were counted under $\times 200$ magnifications in five randomized field views. The number of invading cells was compared between MMI-166 and control (non-MMI-166) conditions. The invasion assay was conducted three times for every cell line.

\section{Angiogenesis assay}

The effects of MMI-166 on glioma-induced angiogenesis were determined by a newly devised research technique based on the angiogenesis kit (Kurabo, Osaka, Japan) (Figure 2). Human endothelial cells and fibroblasts were incubated together according to the kit manufacturer's instructions. We also placed an insert plate with a $1.0-\mu \mathrm{m}$ pore size PET membrane (Falcon HTS Multiwell Insert Systems, BD Biosciences) on the 24-well plate of the angiogenesis kit. Glioma cells were cultured in the insert plate so that soluble angiogenic factors secreted by the glioma cells could affect endothelial cells in the lower chamber. Once the endothelial cells had reached the early stage of lumen formation, MMI-166 was added to the culture solution at varying concentration levels (0.1-100 $\mu \mathrm{M})$ and incubated for 10 days. MMI-166 was not added in the control condition. On day 11 of incubation, the 


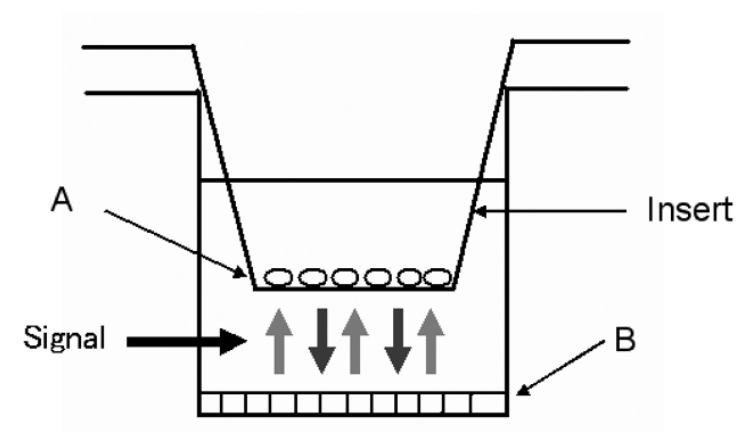

A: glioma cells B: HUVECs with fibroblasts

Figure 2 A new method for in vitro angiogenesis assay. The effects of MMI-166 on glioma-induced angiogenesis were determined by the newly devised research technique based on the angiogenesis kit (Kurabo, Osaka, Japan). Glioma cells were cultured in the insert plate so that soluble angiogenic factors secreted by the glioma cells could affect human umbical vein endothelial cells (HUVECS) in the lower chamber.

cells were fixed in 70\% ethanol, and the anti-CD31 monoclonal antibody (Kurabo) was used as the primary antibody to immunohistochemically stain the vascular lumens. The angiogenesis assay was conducted three times for every cell line.

\section{MTT assay}

For the determination of in vitro growth inhibition of glioma cells by MMI-166, the 3-(4,5-dimethylthiazol-2yl)-2,5-diphenyltetrazolium bromide (MTT) assay was used. Glioma cells $\left(1 \times 10^{4}\right.$ cells/well $)$ were plated in 96 well plates in $100 \mathrm{~mL}$ of the culture medium. After $24 \mathrm{~h}$, MMI-166 (0, 0.1, 1, 10, and $100 \mu \mathrm{M})$ was added to each well. After 24 and $48 \mathrm{~h}$ of incubation with or without MMI-166, $50 \mu \mathrm{L}$ MTT $(2 \mathrm{mg} / \mathrm{mL}$ in PBS) was added to each well at $37^{\circ} \mathrm{C}$ for $3 \mathrm{~h}$, and MTT reduction by viable cells was measured colorimetrically at $570 \mathrm{~nm}$ using a Universal Microplate Reader (EL800; BioTek Instruments, Inc., Winooski, VT, USA). The MTT assay was conducted three times for every cell line.

\section{Effect of MMI-166 on orthotropic implantation}

Athymic female mice (BALB/c $n u / n u$ ) of age 6-8 weeks were obtained from Charles River Japan (Atsugi, Japan). Mice were anesthetized with pentobarbital sodium (60 $\mathrm{mg} / \mathrm{kg}$ intraperitoneally) and injected intracerebrally with T98G cells $\left(1 \times 10^{5}\right)$ through a small hole drilled $2 \mathrm{~mm}$ anterior and $2 \mathrm{~mm}$ lateral to the bregma. Immediately after cell implantation, MMI-166 (100 mg/kg), suspended in a vehicle $(0.9 \% \mathrm{NaCl}$ solution containing $0.5 \%$ carboxymethylcellulose $\mathrm{Na}, 0.9 \%$ benzyl alcohol, and $0.4 \%$ Tween 20) was orally administered to 10 mice five times a week for up to 21 days. The control group $(n=10)$ were orally administered with the vehicle alone. All mice were sacrificed on day 22, and their brains were snap-frozen. Tumour growth of the intracerebral tumours was confirmed by histological evaluation. Serial coronal sections $(30 \mu \mathrm{m})$ were cut from the rostal to caudal edge of the brain tissues containing the tumours by using a cryomicrotome. Tumour size was computed using an Imagepro system (Media Cybernetics Inc., Silver Spring, MD, USA).

For immunohistological examination of angiogenesis, the same T98G xenograft model was used. Mice from both the groups were sacrificed on day 22 , and their brains were harvested and fixed in buffered formalin before embedding in paraffin. Tumour angiogenesis was evaluated using Von Willebrand Factor (VWF) immunostaining. Immunohistochemistry was performed with primary antibodies specific for VWF (ab6994; Abcam Inc., Cambridge, MA, USA). Briefly, 4- $\mu$ m-thick paraffin sections were deparaffinized and dehydrated. The sections were first incubated with appropriate primary antibodies and then with the EnVision ${ }^{+}$System HRP (DAKO, Glostrup, Denmark). Positive staining was detected using diaminobenzidine. For negative controls, the primary antibodies were replaced by a non-specific IgG. All procedures involving animals were approved by the animal care committee of Kochi University and were in accordance with institutional guidelines and Japanese government regulations.

\section{Statistical analysis}

The invasion and angiogenesis assay results obtained from the control and treated groups were statistically analysed by one-way analysis of variance (ANOVA). The statistical significance of tumour volume between the control and treated groups in orthotropic implantation model was analysed using unpaired/paired Student's ttest. In all statistical analyses, $\mathrm{p}<0.05$ was regarded as statistically significant. All values are presented as means \pm standard error (SE).

\section{Results}

\section{Zymography}

The effects of MMI-166 on the gelatinolytic activities of glioma cells were determined by gelatine zymography. The culture supernatants of glioma cell lines were assayed for MMP-2 and MMP-9 gelatinase activities. The glioma cells showed MMP-2 and MMP-9 gelatinase activities. Both the latent and active forms of MMP- 2 and the latent form of MMP-9 were detected in the culture supernatant from glioma cells. We found that MMI-166 reduced the gelatinolytic activities of MMP-2 and MMP-9 in a dosedependent fashion (Figure 3). Although MMP-9 activity was completely controlled by $10 \mu \mathrm{M}$ MMI-166, MMP-2 


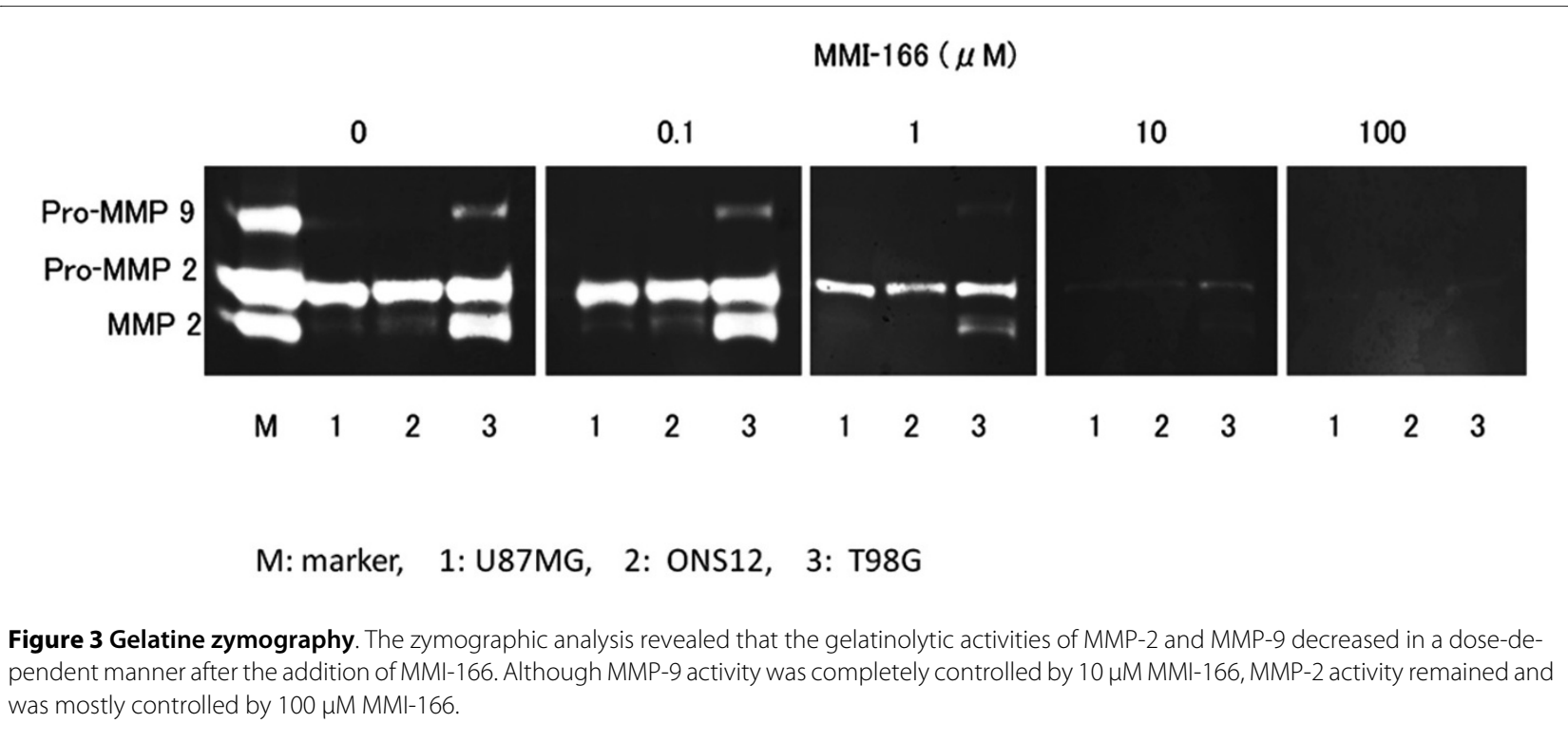

activity remained and was mostly controlled by $100 \mu \mathrm{M}$ MMI-166.

\section{Invasion assay}

The inhibitory effect of MMI-166 was evaluated by the in vitro invasion assay. MMI-166 at various concentrations was added to the medium. Figure 4A shows representative data of T98G. The number of invading glioma cells was compared with the control. The number of invading cells decreased as the concentration of MMI-166 increased. The average number of invading tumour cells in the three glioma cell lines decreased to $55.3 \pm 0.91 \%$ and $45.6 \pm 0.93 \%$, after the addition of 10 and $100 \mu \mathrm{M}$ MMI-166, respectively, compared to the control (Figure 4B). Statistical analysis revealed that invasion of glioma cells was significantly suppressed by MMI-166 ( $\mathrm{p}<$ 0.0001).

\section{Angiogenesis assay}

The inhibitory effect of MMI-166 on glioma-induced neovascularity was evaluated by an in vitro angiogenesis assay. A blood vessel construction image of the entire culture plate was captured by an image scanner. Subsequently, this image was overlaid with a grid image of the same size. The neovascularity was evaluated as the total number of intersections of the vessel and grid in the entire plate (Figure 5A). Figure 5B shows representative data for T98G. The density of neovasculature decreased with an increase in the concentration of MMI-166. The average total number of intersections of the vessel and grid in three glioma cell lines decreased to $37.2 \pm 1.54 \%$ and $6.56 \pm 0.70 \%$ after the addition of 10 and $100 \mu \mathrm{M}$ MMI-166, respectively, when compared with the control (Figure 5C). Statistical analysis revealed that glioma cell- induced neovasularity was significantly suppressed by MMI-166.

\section{MTT assay}

We assessed the inhibitory effect of MMI-166 on growing cultures of the three glioma cell lines by the MTT assay. During the 2-day incubation period, MMI-166 did not show any inhibitory effect on the growth of glioma cells (Figure 6).

\section{Evaluation of implanted tumours}

In the MMI-166 treatment group $(n=10)$, tumour growth was suppressed compared to the control group (n $=10$ ). The average tumour volume was calculated from sequential histological sections (Figure 7A), and was estimated to be $40.8 \pm 0.87 \mathrm{~mm}^{3}$ for the MMI-166 treatment group and $68.4 \pm 1.45 \mathrm{~mm}^{3}$ for the control group ( $<$ 0.0001) (Figure 7B). Immunohistochemical analysis also showed that the number of microvessels (VWF expression) was lower in the MMI-166 treatment group than in the control group (Figure 7C). Histological studies of T98G xenograft model showed that MMI-166 inhibited tumour growth and angiogenesis in vivo.

\section{Discussion}

Tumour growth includes increased synthesis and secretion of several proteases such as cysteine protease, serine protease, and MMP to degrade the ECM. These proteases participate in establishing and maintaining a microenvironment around the tumour so that the tumour cells can survive. Proteolytic action on the ECM is a key step required for the initiation of tumour invasion and angiogenesis. Recent studies suggest that angiogenesis and invasion cooperate in tumour development and involve 


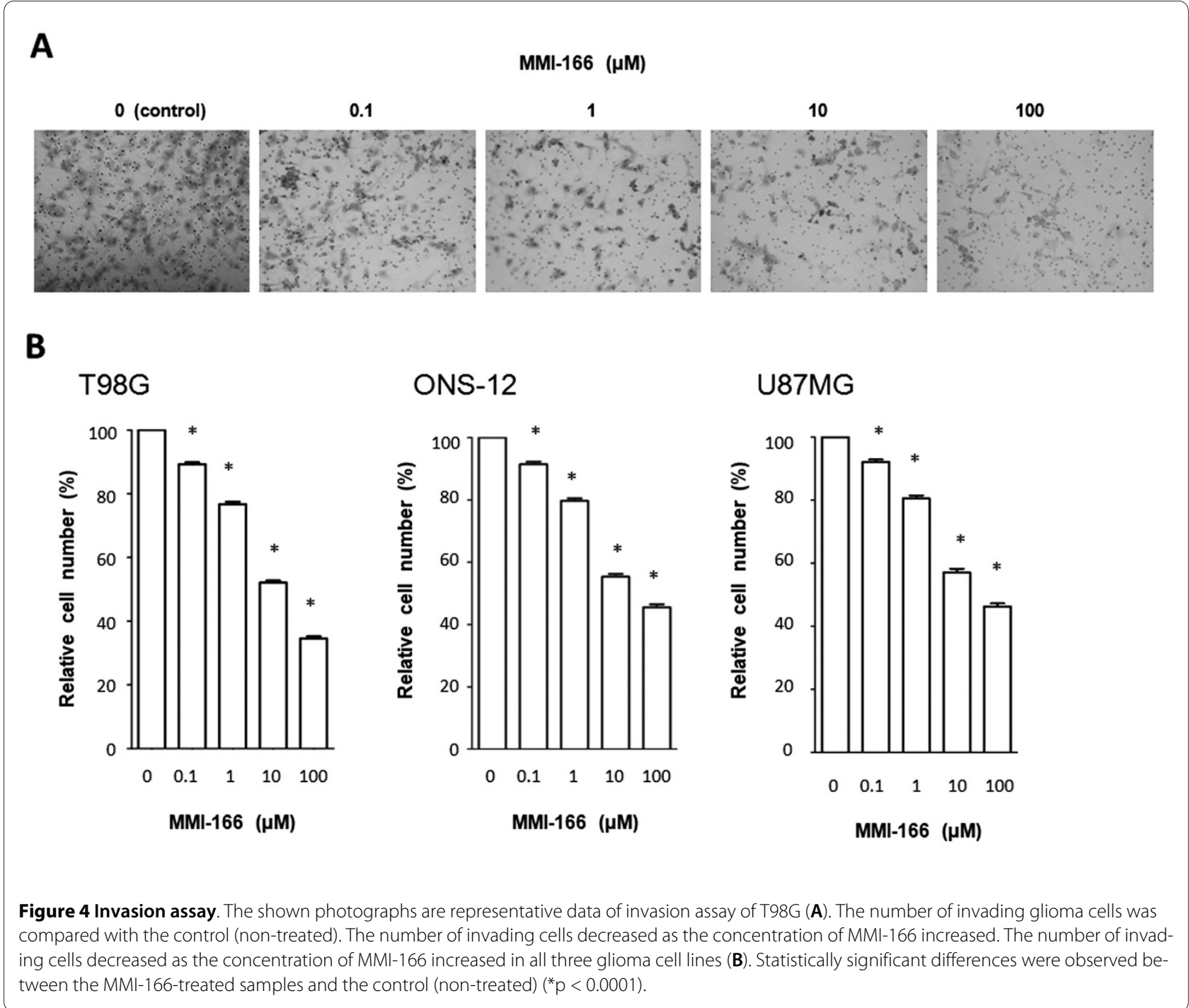

similar biological mechanisms [7]. Furthermore, MMP is strongly related to tumour progression.

MMPs are a family of zinc endopeptidases comprising at least 20 different members. They are classified into five groups on the basis of their structure and substrate specificities [8]. MMPs are secreted as proenzymes that are activated after a peptide of approximately $10 \mathrm{kDa}$ is cleaved. The activity of MMPs is primarily regulated at the transcriptional and translational levels by the secretion by hormones, growth factors, and cytokines [9]. Moreover, there is evidence regarding the modulation of mRNA stability in response to growth factors and cytokines $[7,10]$. Additionally, MMPs are inhibited by specific tissue inhibitor matrix metalloproteinases (TIMPs) and metal chelators [11].

The increased expression of MMPs has been associated with cancers of the head and neck, breast, lung, stomach, and pancreas [12-16]. In particular, MMP-2 and MMP-9 were reported to correlate with tumour grade and metastasis [17]. On the basis of the evidence that TIMPs can interfere with experimental metastasis, the role of MMPs in tumour progression has been determined [18]. However, the role of MMPs and TIMPs in cancer is much more complicated than that suggested initially. For example, increased TIMP-1 levels in human cancer tissues have been associated with poor prognoses [19]. It is uncertain whether this reflects growth-potentiating properties or some other undetermined property of TIMPs [20]. Other experimental studies involving cancer cells transfected with TIMP-1 cDNA demonstrated that MMPs act primarily to alter the extracellular environment to allow sustained cancer cell growth at an ectopic site as opposed to having the specific role of allowing the cells to extravasate from the blood stream [21]. Furthermore, in some experimental tumour systems, increased MMP production did not correlate with increased metas- 

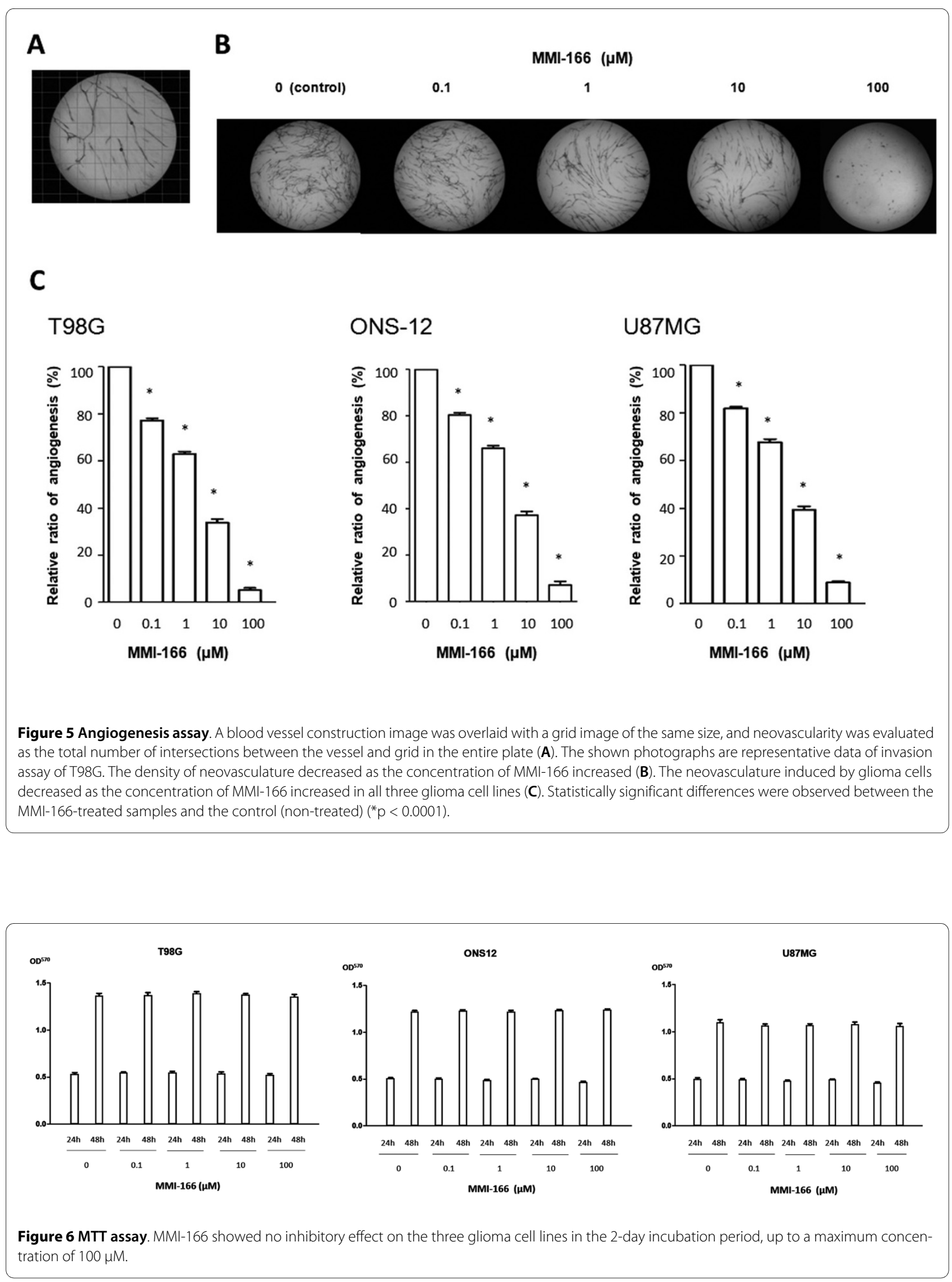


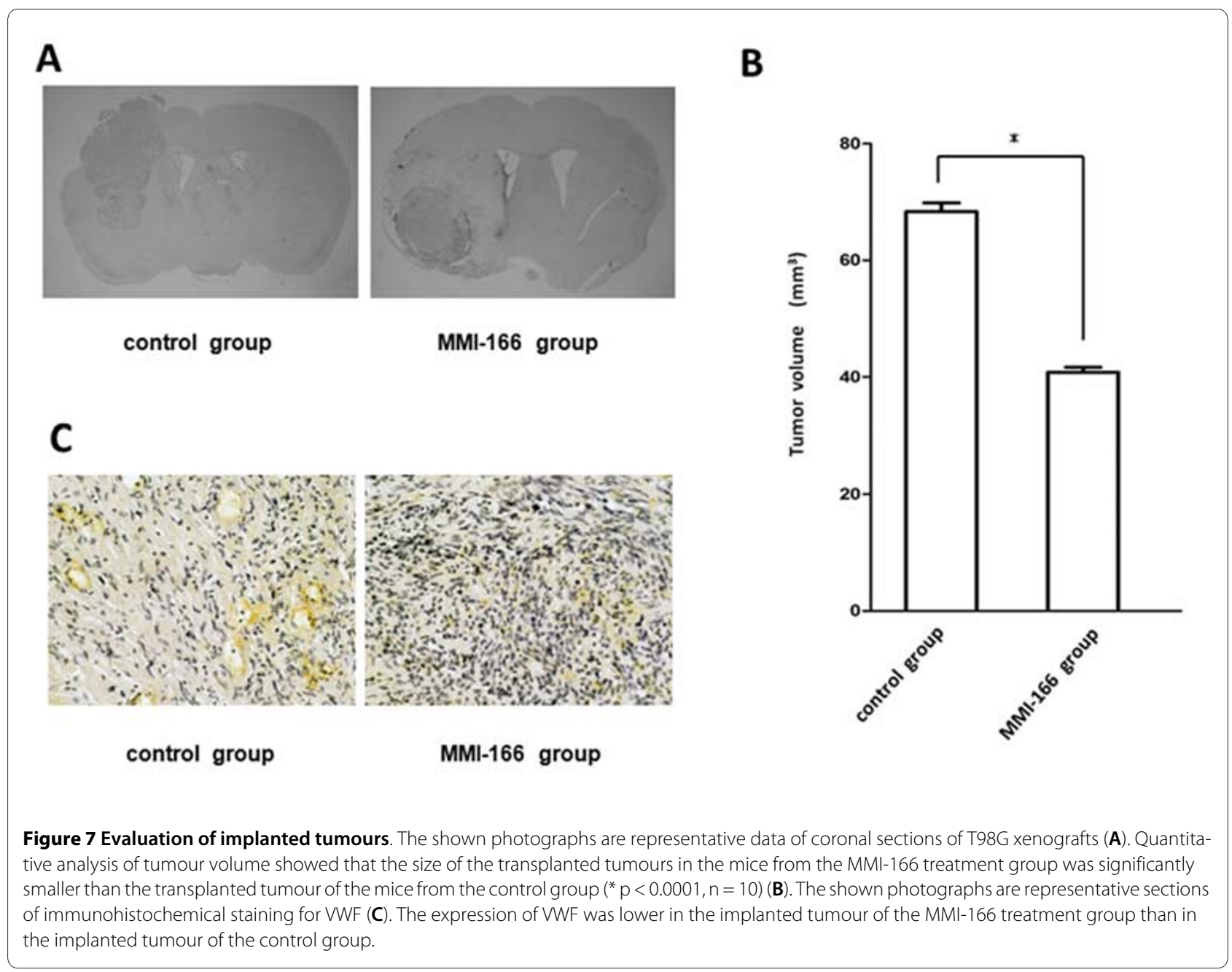

tasis [22]. One possible explanation for this finding is that excess proteolysis might degrade matrix signals and receptors, thereby disrupting cell matrix interactions and inhibiting migration [23].

One of the early events in the transition of a tumour from the pre-neoplastic to the neoplastic state is the ability of the tumour to promote angiogenesis [24]. The results of numerous experimental studies support the concept that the growth of new blood vessels is required for continued tumour growth [25]. Tumour angiogenesis is a complex process that requires 1) the degradation of the basement membrane and ECM surrounding the blood vessels, 2) chemotaxis of endothelial cells towards an angiogenic stimulus, 3) proliferation of the endothelial cells, and 4) remodelling of the basement membrane as new blood vessels form. This remodelling is considered to result from MMP activity [26]. Endothelial cells produce MMP-1, MMP-2, MMP-3, and membrane-type MMP (MT-MMP). Recent studies revealed that MMP-2 and MT-MMP have a crucial role in angiogenesis (2). The treatment of human umbilical vein endothelial cells with phorbol ester (namely, phorbol 12-myristate 13-acetate; PMA) leads to MMP-2 activation and induction of MTMMP [27]. This is accompanied by the formation of multicellular tube structures when cells are cultured in a collagen gel [28].

Malignant gliomas are highly aggressive tumours characterized by extensive brain invasion and strong angiogenesis. Recent proteinase profiling studies have demonstrated the over-expression of the serine urokinase-type plasminogen activator (uPA) and its receptor (uPAR), cysteine protease cathepsin B, MMP-2, and MMP-9 in high grade astrocytomas compared with low grade astrocytomas or the normal brain. In particular, MMP-2 and MMP-9 are the two most abundant MMPs found in gliomas [29]. Therefore, it has been proposed that MMP-2 and MMP-9 inhibitors can act as potential drugs for the treatment of gliomas. Selective gene suppression of MMP-2 or MMP-9 dramatically reduces the invasive phenotype of gliomas [30,31].

A number of MMP inhibitors, including Batimastat [3], Marimastat [4], and AG3340 [32], have entered clinical 
development, but none have been licensed. Disappointing results were reported for phase III studies in patients with non-small cell lung cancer stage IIIB/IV [33], metastatic breast cancer [34], and advanced pancreatic adenocarcinoma [35]. However, it is still thought that MMP inhibitors may have therapeutic potential for the earlier stages of cancer or prevention of cancer metastasis. Although MMP inhibitor has not cytotoxic anticancer effect, MMP inhibitor has cytostatic and anti-angiogenic effects. Furthermore, MMP inhibitor has few side effects as compared with cytotoxic anticancer drug and also has the merit of controlling a cancer more effectively when it was used together with other cytotoxic drugs.

As for glioma, AG3340 and SI-27 [36] were preclinically studied. In vivo study using SCID-NOD mouse, AG3340 decreased tumour size of transplanted U87 glioma by $78 \%$ compared with controls after 31 days [37]. Systemic administration of SI-27 in U251MG xenograft mouse showed a statistically significant increase in survival time compared with the controls receiving carrier (median survival, 47.3 versus $32.6 \mathrm{~d}$ ). There was also a decrease in MMP activity, tumour cell invasion, and neovascularization [36]. Therefore, it is thought MMP inhibitors may have therapeutic potential for gliomas.

MMI-166 is a third generation MMP inhibitor having an $N$-arylsulfonyl- $\alpha$ - aminocarboxylate zinc binding group. It is an MMP-2, -9 and -14 selective inhibitor that spares MMP-1, -3 and -7. The key structural feature exemplified by MMI-166 is the "deep" aryl substitution. While it has shown anticancer activity in several animal models of human cancer, there are no data as to its effect on malignant gliomas. Therefore, we aimed to examine the effect of MMI-166 on malignant glioma cells.

So for, there is no data about the clinical trial of MMI166. However, S-3304 (Shionogi \& Co., Ltd; Osaka, Japan), a relative compound of MMI-166, has shown a good safety profile and good systemic exposure when administered orally in doses up to $800 \mathrm{mg}$ twice daily for 10 to 17 days in healthy volunteers [41]. A phase I pharmacokinetic and pharmacodynamic study of S-3304 in patients with advanced and refractory solid tumours showed that S-3304 is safe, well tolerated, and achieves plasma concentrations above those required to inhibit MMP-2 and MMP-9 [42].

In the present study, we used a new in vitro angiogenesis assay. Tumour-induced angiogenesis is usually performed by the dorsal air sac-chamber assay or the chick choriallantoic membrane assay (CAM assay). However, these two methods need animals and are slightly complicated. An in vitro angiogenesis assay that does not require an animal is usually carried out by adding the tumour culture supernatant to an angiogenesis kit in which the endothelial cells were set. However, there is no direct traffic between the endothelial and tumour cells in this technique. In contrast, our new method enables direct trafficking between the endothelial and tumour cells through secreting factors from each cell type.

\section{Conclusion}

The present study showed that MMI-166 reduced the activities of MMP-2 and MMP-9 and significantly inhibited the invasive and angiogenic activities of glioma cells in vitro and in vivo. Furthermore, MMI-166 inhibited tumour growth in vivo. It is possible that MMI-166 potentiates the suppression of glioma progression.

\section{Competing interests}

The authors declare that they have no competing interests.

\section{Authors' contributions}

$\mathrm{HN}$ was responsible for the study design, interpretation of the data and revision of the manuscript. TY and KS supervised the studies and helped to revise the manuscript. All readers read and approved the final manuscript.

\section{Acknowledgements}

The authors declare that they have no acknowledgements.

\section{Author Details}

Department of Neurosurgery, Kochi Medical School Kochi University, Nankoku, Japan

Received: 3 February 2010 Accepted: 29 June 2010

Published: 29 June 2010

\section{References}

1. Liotta LA, Steeg PS, Stetler-Stevenson WG: Cancer metastasis and angiogenesis: an imbalance of positive and negative regulation. Cell 1991, 64:327-336.

2. Stetler-Stevenson WG, Aznavoorian S, Liotta LA: Tumor cell interactions with the extracellular matrix during invasion and metastasis. Annu Rev Cell Bio 1993, 19:541-573.

3. Tonn JC, Kerkau S, Hanke A, Bouterfa H, Mueller JG, Wagner S, Vince GH, Roosen K: Effect of synthetic matrix-metalloproteinase inhibitors on invasive capacity and proliferation of human malignant gliomas in vitro. Int J Cancer 1999, 80:764-772.

4. Groves MD, Puduvalli VK, Hess KR, Jaeckle KA, Peterson P, Yung WK, Levin VA: Phase II trial of temozolomide plus the matrix metalloproteinase inhibitor, marimastat, in recurrent and progressive glioblastoma multiforme. J Clin Oncol 2002, 20:1383-1388.

5. Qian LW, Mizumoto K, Urashima T, Nagai E, Maehara N, Sato N, Nakajima M, Tanaka M: Radiation-induced increase in invasive potential of human pancreaticcancer cells and its blockade by a matrix metalloproteinase inhibitor, CGS27023. Clin Caner Res 2002, 8:1223-1227.

6. Maekawa R, Maki H, Wada T, Yoshida H, Nishida-Nishimoto K, Okamoto H, Matsumoto Y, Tsuzuki H, Yoshioka T: Anti-metastatic efficacy and safety of MMI-166, a selective matrix metalloproteinase inhibitor. Clin Exp Metastasis 2000, 18:61-66.

7. Skobe M, Rockwell P, Goldstein N, Vosseler S, Fusenig NE: Halting angiogenesis suppresses carcinoma cell invasion. Nat Med 1997, 3:1222-1227.

8. Matrisian LM: Metalloproteinases and their inhibitors in matrix remodeling. Trends Genet 1990, 6:121-125

9. Rougier JP, Moullier P, Piedagnel R, Ronco PM: Hyper-osmolality suppresses but TGFß1 increases MMP-9 in human peritoneal mesothelial cells. Kidney Int 1997, 51:337-347.

10. Atula S, Grenman R, Syrjänen S: Fibroblasts can modulate the phenotype of malignant epithelial cells in vitro. Exp Cell Res 1997, 235:180-187.

11. Edwards DR, Beaudry PP, Laing TD, Kowal V, Leco KJ, Leco PA, Lim MS: The roles of tissue inhibitors of metallo- proteinases in tissue remodelling and cell growth. Int J Obes Relat Metab Disord 1996, 20:9-15.

12. Yoshizaki T, Sato H, Maruyama Y, Murono S, Furukawa M, Park CS, Seiki M: Increased expression of membrane type-1 matrix metalloproteinase in head and neck carcinoma. Cancer 1997, 79:139-144. 
13. Davies B, Miles DW, Happerfield LC, Naylor MS, Bobrow LG, Rubens RD, Balkwill FR: Activity of type IV collagenases in benign and malignant breast disease. Br J Cancer 1993, 67:1126-1131.

14. Tokuraku M, Sato H, Murakami S, Okada Y, Watanabe Y, Seiki M: Activation of the precursor of gelatinase A/72 kDa typelV collagenase/MMP-2 in lung carcinomas correlates with the expression of membrane-type matrix metalloproteinase (MT-MMP) and with lymph node metastasis. Int J Cancer 1995, 64:355-359.

15. Nomura H, Sato H, Seiki M, Mai M, Okada Y: Expression of membranetype matrix metalloproteinase in human gastric carcinomas. Cancer Res 1995, 55:3263-3266.

16. Bramhall SR: The matrix metalloproteinases and their inhibitors in pancreatic cancer. Int J Pancreatol 1997, 21:1-12.

17. Sillem M, Prifti S, Koumouridis A, Runnebaum B: Invasiveness corresponds to differentiation rather than to proteinase secretion in endometrial cancer cell lines. Eur J Gynaec Oncol 1999, 20:367-370.

18. DeClerck YA, Imren S: Protease inhibitors: role and potential therapeutic use in human cancer. Eur J Cancer 1994, 14:2170-2180.

19. Lu XQ, Levy M, Weinstein IB, Santella RM: Immunological quantitation of levels of tissue inhibitor of metalloproteinase-1 in human colon cancer. Cancer Res 1991, 51:6231-6235.

20. Hayakawa T, Yamashita K, Ohuchi E, Shinagawa A: Cell growthpromoting activity of tissue inhibitor of metalloproteinases-2 (TIMP-2). J Cell Sci 1994, 107:2373-2379.

21. Chambers AF, Matrisian LM: Changing views of the role of matrix metalloproteinases in metastasis. J Nat/ Cancer Inst 1997, 89:1260-1270.

22. Zucker S, Lysik RM, Malik M, Bauer BA, Caamano J, Klein-Szanto AJ: Secretion of gelatinases and tissue inhibitors of metalloproteinases by human lung cancer cell lines and revertant cell lines: not an invariant correlation with metastasis. Int J Cancer 1992, 52:366-371.

23. Madlener M, Parks WC, Werner S: Matrix metalloproteinases (MMPs) and their physiological inhibitors (TIMPs) are differentially expressed during excisional skin wound repair. Exp Cell Res 1998, 242:201-210.

24. Fang J, Shing Y, Wiederschain D, Yan L, Butterfield C, Jackson G, Harper J, Tamvakopoulos G, Moses MA: Matrix metalloproteinase-2 is required for the switch to the angiogenic phenotype in a tumor model. Proc Natl Acad Sci USA 2000, 97:3884-3889

25. Folkman J: The role of angiogenesis in tumor growth. Semin Cancer Biol 1992, 3:65-71

26. Moscatelli D, Rifkin DB: Membrane and matrix localization of proteinases: a common theme in tumor cell invasion and angiogenesis. Biochim Biophys Acta 1988, 948:67-85.

27. Foda HD, George S, Conner C, Drews M, Tompkins DC, Zucker S: Activation of human umbilical vein endothelial cell progelatinase $A$ by phorbol myristate acetate: a protein kinase C-dependent mechanism involving a membrane-type matrix metalloproteinase. Lab Invest 1996, 74:538-545.

28. Haas TL, Madri JA: Extracellular matrix-driven matrix metalloproteinase production in endothelial cells: implications for angiogenesis. Trends Cardiovasc Med 1999, 9:70-77.

29. Forsyth PA, Wong H, Laing TD, Rewcastle NB, Morris DG, Muzik H, Leco KJ, Johnston RN, Brasher PM, Sutherland G, Edwards DR: Gelatinase A (MMP2), gelatinase B (MMP-9) and membrane type matrix metalloproteinase-1 (MT1-MMP) are involved in different aspects of the pathophysiology of malignant glioma. Br J Cancer 1999, 79:1828-1835.

30. Deryugina El, Bourdon MA, Luo GX, Reisfeld RA, Strongin A: Matrix metallo- proteinase-2 activation modulates glioma cell migration. J Cell Sci 1997, 110:2473-2482

31. Kondraganti S, Mohanam S, Chintala SK, Kin Y, Jasti SL, Nirmala C, Lakka SS, Adachi Y, Kyritsis AP, Ali-Osman F, Sawaya R, Fuller GN, Rao JS: Selective suppression of matrix metalloproteinase-9 in human glioblastoma cells by antisense gene transfer impairs glioblastoma cell invasion. Cancer Res 2000, 60:6851-6855.

32. Price A, Shi Q, Morris D, Wilcox ME, Brasher PM, Rewcastle NB, Shalinsky D, Zou H, Appelt K, Johnston RN, Yong VW, Edwards D, Forsyth P: Marked inhibition of tumor growth in a malignant glioma tumor model by novel synthetic matrix metalloproteinase inhibitor AG3340. Clin Cancer Res 1999, 5:845-854.

33. Bissett D, O'Byrne KJ, von Pawel J, Gatzemeier U, Price A, Nicolson M, Ercier R, Mazabel E, Penning C, Zhang MH, Collier MA, Shepherd FA: Phase III study of matrix Metalloproteinase inhibitor prinomastat in non-smallcell lung cancer. J Clin Oncol 2005, 23:842-849.

34. Sparano JA, Bernardo P, Stephenson P, Gradishar WJ, Ingle JN, Zucker S, Davidson NE: Randomized phase III trial of marimastat versus placebo in patients with metastatic breast cancer who have responding or stable disease after first-line chemotherapy: Eastern Cooperative Oncology Group trial E2196. J Clin Oncol 2004, 22:4683-4690.

35. Moore MJ, Hamm J, Dancey J, Eisenberg PD, Dagenais M, Fields A, Hagan K, Greenberg B, Colwell B, Zee B, Tu D, Ottaway J, Humphrey R, Seymour L: Comparison of gemcitabine versus the matrix metalloproteinase inhibitor BAY12-9566 in patients with advanced or metastatic adenocarcinoma of the pancreas: a phase III trial of the National Cancer Institute of Canada Clinical Trials Group. J Clin Oncol 2003, 21:3296-302.

36. Yoshida D, Takahashi $\mathrm{H}$, Teramoto A: Inhibition of glioma angiogenesis and invasion by SI-27, an anti-matrix metalloproteinase agent in a rat brain tumor model. Neurosurgery 2004, 54(5):1213-20. discussion 1220-1

37. Price A, Shi Q, Morris D, Wilcox ME, Brasher PM, Rewcastle NB, Shalinsky D, Zou H, Appelt K, Johnston RN, Yong VW, Edwards D, Forsyth P: Marked inhibition of tumor growth in a malignant glioma tumor model by a novel synthetic matrix metalloproteinase inhibitor AG3340. Clin Cancer Res 1999, 5(4):845-54

38. Oba K, Konno H, Tanaka T, Baba M, Kamiya K, Ohta M, Kaneko T, Shouji T, Igarashi A, Nakamura S: Prevention of liver metastasis of human colon cancer by selective matrix metalloproteinase inhibitor MMI-166. Cancer Lett 2002, 175:45-51.

39. Iwasaki M, Nishikawa A, Fujimoto T, Akutagawa N, Manase K, Endo T, Yoshida K, Maekawa R, Yoshioka T, Kudo R: Anti-invasive effect of MMI166 , a new selective matrix metalloproteinase inhibitor, in cervical carcinoma cell lines. Gynecol Oncol 2002, 85:103-107.

40. Fujino $H$, Kondo $K$, Ishikura $H$, Maki H, Kinoshita $H$, Miyoshi $T$, Takahashi $Y$, Sawada N, Takizawa H, Nagao T, Sakiyama S, Monden Y: Matrix metalloproteinase inhibitor MMI-166 inhibits lymphogenous metastasis in an orthotopically implanted model of lung cancer. $\mathrm{Mol}$ Cancer Ther 2005, 4:1409-1416.

41. Mant TG, Bradford D, Amin DM, Pisupati J, Kambayashi Y, Yano Y, Tanaka K, Yamada-Sawada T: Pharmacokinetics and safety assessments of highdose and 4-week treatment with S-3304, a novel matrix metalloproteinase inhibitor, in healthy volunteers. Br J Clin Pharmacol 2007, 63:512-526.

42. Chiappori AA, Eckhardt SG, Bukowski R, Sullivan DM, Ikeda M, Yano Y, Yamada-Sawada T, Kambayashi Y, Tanaka K, Javle MM, Mekhail T, O'bryant CL, Creaven PJ: A phase I pharmacokinetic and pharmacodynamic study of s-3304, a novel matrix metalloproteinase inhibitor, in patients with advanced and refractory solid tumors. Clin Cancer Res 2007, 13:2091-2099.

Pre-publication history

The pre-publication history for this paper can be accessed here: http://www.biomedcentral.com/1471-2407/10/339/prepub

doi: 10.1186/1471-2407-10-339

Cite this article as: Nakabayashi et al., Anti-invasive and antiangiogenic effects of MMI-166 on malignant glioma cells BMC Cancer 2010, 10:339

\section{Submit your next manuscript to BioMed Centra and take full advantage of:}

- Convenient online submission

- Thorough peer review

- No space constraints or color figure charges

- Immediate publication on acceptance

- Inclusion in PubMed, CAS, Scopus and Google Scholar

- Research which is freely available for redistribution 